Article

\title{
From Oligo(Phenyleneethynylene) Monomers to Supramolecular Helices: The Role of Intermolecular Interactions in Aggregation
}

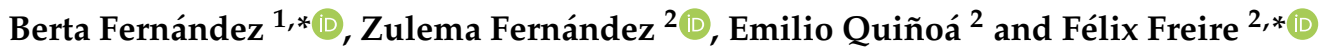 \\ 1 Departamento de Química Física, Universidade de Santiago de Compostela, \\ 15782 Santiago de Compostela, Spain \\ 2 Centro Singular de Investigación en Química Biolóxica e Materiais Moleculares (CiQUS), Departamento de \\ Química Orgánica, Universidade de Santiago de Compostela, 15782 Santiago de Compostela, Spain; \\ zulema.fernandez@usc.es (Z.F.); emilio.quinoa@usc.es (E.Q.) \\ * Correspondence: berta.fernandez@usc.es (B.F.); felix.freire@usc.es (F.F.)
}

Citation: Fernández, B.;

Fernández, Z.; Quiñoá, E.; Freire, F. From Oligo(Phenyleneethynylene) Monomers to Supramolecular Helices: The Role of Intermolecular Interactions in Aggregation. Molecules 2021, 26, 3530. https://doi.org/ $10.3390 /$ molecules 26123530

Academic Editors: Jorge M.

C. Marques, Frederico

Vasconcellos Prudente and

Fernando Pirani

Received: 8 May 2021

Accepted: 5 June 2021

Published: 9 June 2021

Publisher's Note: MDPI stays neutral with regard to jurisdictional claims in published maps and institutional affiliations.

Copyright: (c) 2021 by the authors. Licensee MDPI, Basel, Switzerland. This article is an open access article distributed under the terms and conditions of the Creative Commons Attribution (CC BY) license (https:// creativecommons.org/licenses/by/ $4.0 /)$.

\begin{abstract}
Supramolecular helices that arise from the self-assembly of small organic molecules via non-covalent interactions play an important role in the structure and properties of the corresponding materials. Here we study the supramolecular helical aggregation of oligo(phenyleneethynylene) monomers from a theoretical point of view, always guiding the studies with experimentally available data. In this way, by systematically increasing the number of monomer units, optimized n-mer geometries are obtained along with the corresponding absorption and circular dichroism spectra. For the geometry optimizations we use density functional theory together with the B3LYP-D3 functional and the $6-31 G^{* *}$ basis set. For obtaining the spectra we resort to time-dependent density functional theory using the CAM-B3LYP functional and the 3-21G basis set. These combinations of density functional and basis set were selected after systematic convergence studies. The theoretical results are analyzed and compared to the experimentally available spectra, observing a good agreement.
\end{abstract}

Keywords: oligo(phenyleneethynylene); monomer aggregation; supramolecular helices; density functional theory and time-dependent density functional theory calculations; geometry optimizations; absorption spectra; electron circular dichroism spectra

\section{Introduction}

Supramolecular helices are obtained through self-assembly of small organic molecules via non-covalent interactions, which will be responsible for their dynamic and reversible character. These interactions determine the aggregate growth mechanism and tune the supramolecular structure. Therefore, taking into account the structure/function relationship, the corresponding materials will have interesting applications in fields such as: catalysis [1-5], nanoelectronics [6-11], or pharmaceutics [12-15], among others. Due to their high interest, a considerable number of experimental studies on supramolecular aggregates have been reported in the literature. It is worth mentioning the work by Meijer et al. [16,17] where the formation mechanisms of several aggregates have been studied in detail and the key role played by non-covalent forces was pointed out.

The structural determination at molecular and intermolecular levels is crucial to understand the properties of the aggregates and is challenging from both the experimental and the computational point of view. Experimental methods like electron circular dichroism (ECD), X-ray diffraction, atomic force microscopy (AFM), infrared (IR) spectroscopy or Raman spectroscopy provide valuable information to study the aggregates, but mostly the information obtained is not enough or not clear enough to solve the tridimensional structure of the aggregate [18-20]. Sometimes, even in the optimal experimental conditions and through the combination of several experimental techniques, it is not possible to put all the 
information together and determine the aggregate morphology. Therefore, computational studies could play a key role in the structural analysis of the supramolecular aggregates, although the large size of the systems under investigation makes the structural and spectroscopic computations challenging. To surpass this limitation, and taking into account the possible lack of accuracy of the different theoretical methods, it is necessary to combine experimental and theoretical approaches. Following this line, Díaz-Cabrera et al. [21] studied the self-assembly of achiral and chiral 1,3,5-triphenylbenzenetricarboxamides. In a similar way, Greciano et al. [22] analyzed the self-assembly of $\mathrm{N}$-annulated perylene bisimides [PBIs], showing the important role of long-range van der Waals and dipoledipole electrostatic interactions in the aggregation mechanism of compounds that lack $\mathrm{H}$-bonding groups.

Among all supramolecular helices, those formed by building blocks containing $\pi$-conjugated cores-perylenebisimides [PBIs] [23-25], benzene-1,3,5-tricarboxiamides [BTAs] [26-28], oligo(phenyleneethynylene)s [OPEs] [29-35], peri-hexabenzenecoronenes [HBCs] [36-38] and others [39] — attract wide interest due to their potential optical and electronic properties. In these molecules the self-assembly is led by $\pi-\pi$ interactions in addition to other non-covalent forces. Moreover, the introduction of long alkyl chains ensures good solubility of the building blocks in non-polar solvents and triggers the formation of supramolecular helical aggregates. Regarding this, linear OPEs have drawn much attention not only for their intrinsic supramolecular properties, but also for the possibility of being used in molecular electronic devices [40,41]. Although several studies in the literature use linear achiral OPEs as building blocks for generating supramolecular scaffolds (the most representative ones bearing long alkyl chains on both edges of the OPE building blocks, or even on all the aromatic rings [42-45]), few chiral examples are found [29,46]. Recently, we have reported a combined experimental-theoretical study on the determination of the aggregation mechanism in a short, chiral and rigid OPE [(S)-1] [47]. We concluded that the polymerization process of the monomer led to a remarkable aggregation mechanism, where either a thermodynamic aggregate or a kinetically trapped one-both showing opposite supramolecular chiralities - could selectively be obtained just by modifying the aggregation conditions. In this way, while the formation of short $P$-twisted oligomers produced in-plane aggregation to generate brick-like nanostructures, the formation of large helical supramolecular polymers yielded single-chain $M$-type columnar helical aggregates.

Herein, we will analyze in detail the aggregation process of (S)-1 (Figure 1a) that results in the formation of sheet-like nanostructures (Figure 1b,c). To perform this investigation the computational studies will be guided with our experimentally available data. First, different morphologies of the aggregate will be generated by stacking the monomers in different orientations and, after determining the optimal one, the number of monomer units in the aggregate will be systematically increased. Computational studies on these systems will allow us to analyze the stability of these aggregates and the intermolecular forces involved in the supramolecular assembly-mainly H-bonding and $\pi-\pi$ interactions. Additionally, from the obtained geometries it will be possible to calculate the absorption and circular dichroism spectra. A comparison of these data to the experimentally obtained will be performed looking for the best fit to propose a 3D-model for the aggregate.

The manuscript is organized as follows: in Section 2 we give the computational details, in Section 3 the results are presented and discussed, and in the last Section we summarize and conclude. 
a)

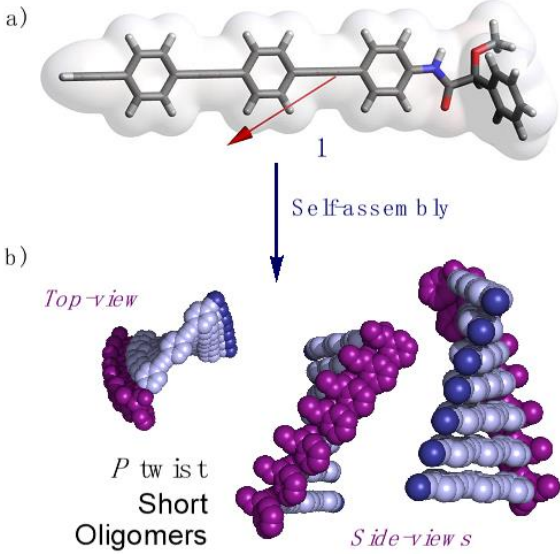

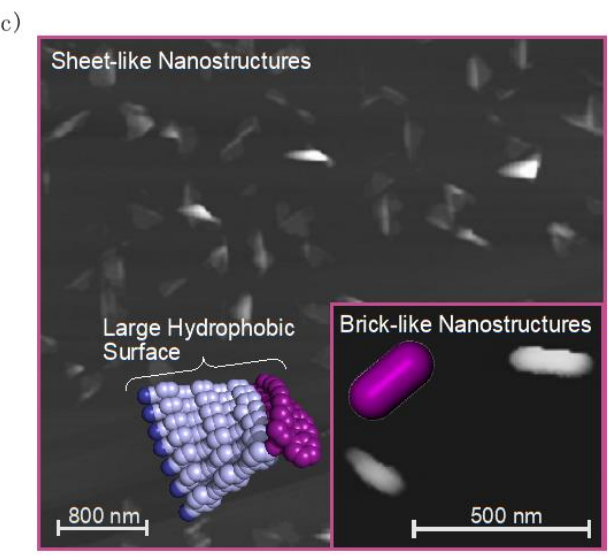

Figure 1. (a) Oligo(phenyleneethynylene) (OPE) [(S)-1] chemical structure, dipole moment and electrostatic potential on the 0.001 au isodensity surface (vdW surface). (b) Supramolecular aggregate of (S)-1 describing a $P$-twisted oligomer helix. (c) AFM image for the obtained sheet-like nanostructures and inset of the brick-like nanostructures generated by the aggregation of several $P$-twisted oligomer helices.

\section{Computational Details}

To study the role of intermolecular forces in aggregation, we first analyzed the conformational composition of monomer $(S)-\mathbf{1}(n=1)$. Once the geometries of the relevant conformers are optimized, we studied a dimer of the optimized monomer $(n=2)$, which could be built up either with the chiral moieties stacked one on top of the other (headto-head, hh-geometry) or in an alternate fashion (head-to-tail, ht-geometry). Next, by linking two dimer geometries we created the 4-mers $(n=4)$ and finally, from the 4-mers, we constructed the 8-mers $(n=8)$. These sequential additions allowed us to model a helix and study the evolution of its ECD spectrum when the length of the helix is increased. In a previous work, we analysed the ECD spectra of poly(phenylacethylene) (PPA) oligomers [48] by increasing the number of monomer units (n) in the oligomer. From these studies it was concluded that 8-10 monomers were enough to describe the helix generated by the polymers under investigation.

As a first step in the geometry search, for $n=1-4$ we carried out molecular dynamics (MD) calculations using the Conformer Rotamer Ensemble Sampling Tool (CREST) program [49] to obtain the most stable and convenient conformers in terms of stacking. The details of the MD simulations are provided in the Supplementary Materials. After selecting the conformers, we further optimized their geometries using Density Functional Theory (DFT) [50,51], together with the B3LYP functional [52,53] with the D3 correction for dispersion [54], and the 6-31G** basis set [55]. We selected this methodology bearing in mind that the main objective of this work is the study of aggregates of monomers where dispersion plays an important role.

To get more insight into the nature of the supramolecular forces, the interaction energies, $E_{A-B}^{\{A-B\}}$ in Equation (1) were evaluated for the dimer at the DFT(B3LYP-D3)/6$31 \mathrm{G}^{* *}$ level of theory using the supermolecular approach and the counterpoise method to correct for basis set superposition error [56];

$$
\Delta E_{A-B}^{\{A-B\}}=E_{A-B}^{\{A-B\}}-E_{B}^{\{A-B\}}-E_{A}^{\{A-B\}},
$$

where $E_{B}^{\{A-B\}}$ and $E_{A}^{\{A-B\}}$ are the energies of monomer $B$ and $A$, respectively, and superscript $\{A-B\}$ denotes that the energies are evaluated in the dimer basis set.

Additionally, for the most stable conformer of the dimer, in order to elucidate the different contributions to the interaction energy, a non-covalent interaction (NCI) analysis [57] was carried out. The NCI index analysis is based on the density $(\rho)$ and its derivatives. The non-covalent interactions can be identified from the reduced density gradient (s) and the sign of the second density Hessian eigenvalue $\left(\lambda_{2}\right)$ is used to assign the different interac- 
tions. In this way, plots of the variation of s versus $\left(\lambda_{2}\right.$ sign $) \times \rho$ show the nature of the interactions, since this last term can characterize the strength of the interaction through $\rho$ and its nature via the $\lambda_{2}$ sign.

For the 4-mer we obtained the interaction energy by generalizing the expression in Equation (1). Additionally, two-body contributions and cooperative effects are estimated, using the methodology described in reference [58]. In this way, the two body contributions, $\Delta E^{(2)}$, are given by

$$
\Delta E^{(2)}=\sum_{i>j}^{4} \Delta E_{i j}=\sum_{i>j}^{4}\left(E_{i j}^{\{i-j\}}-\sum_{k=i, j} E_{k}^{\{i-j\}}\right),
$$

where $i$ and $j$ are indices that go over the 4 monomers in the 4-mer, and superscript $\{I-j\}$ denotes that the dimer basis set is used for the calculations. The total many-body contributions are given as the difference between the complex interaction energy and the two- body contributions in Equation (2). Determining the size of these contributions is important because, on the one hand, they can constitute a considerable part of the interaction energy, therefore playing an important role in the interaction, and on the other hand, considering that many interaction potentials for large molecules are based only on two-body terms, we can check how good a description like this is in the case of the present complexes.

In addition, for the aggregates under investigation it is known that intermolecular H-bonding plays a key role in their formation and stabilization. The stacking of molecules through a hydrogen-bond-network can cause a significant shortening of the hydrogen-bond donor-acceptor distance and an increase of the hydrogen bond strength, whenever a new molecule is incorporated to the supramolecular aggregate [59]. This phenomenon, known as the cooperative effect, has been widely studied in the context of interaction energies, equilibrium structures and spectra [58]. Considering this, here we have also estimated the cooperative effect, defining it with respect to the interaction between monomer $\mathrm{A}$ and monomer $\mathrm{B}$ in the ABCD 4-mer aggregate as:

$$
\Delta E_{A B C D}^{c o o p}=\Delta E_{A-B C D}-\Delta E_{A B},
$$

being

$$
\Delta E_{A-B C D}=E_{A B C D}-E_{A}-E_{B C D}
$$

and correcting for basis set superposition error.

To evaluate the absorption and ECD spectra, we considered the size of the supramolecular helical structures under investigation and the results of previous studies on covalently bonded polymers [60] that showed the efficiency of employing Time-Dependent DFT (TD-DFT) [61] together with the CAM-B3LYP density functional [62] and the 3-21G basis set [63]. For $n=1-4$ we included 80 excitation energies in the calculations and 20 for the 8-mer. To get more insight into the main spectral bands, we evaluated the electron density differences for the corresponding main transitions at the TD-DFT(CAM-B3LYP)/3-21G level of theory. For the $n=1-4$ DFT(B3LYP-D3) $/ 6-31 G^{* *}$ optimized structures we also evaluated the variation of the IR spectra at the same level of theory.

Due to the reduced size of the monomer, in this case we additionally performed calculations of the UV and ECD spectra with the correlation consistent valence triple zeta (cc-VTZ) basis set and at the experimental X-ray geometry in order to check for geometry and basis set convergence in our results. Also, to get more insight into the lowest energy absorption band of the UV spectrum we evaluated the corresponding vibronic transitions using the CAM-B3LYP functional with the D3 dispersion correction and the $6-31 G^{* *}$ basis set.

The optimized geometries, IR and vibronic spectra were obtained with the Gaussian16 program [64]; all the UV-Vis and ECD spectra were evaluated with the ORCA program [65]; the analysis of the noncovalent interactions was carried out with the NCIPLOT 
program [57]. To plot the spectra, we used the GABEDIT program [66], and for the density differences Avogadro [67]. For the UV-Vis and ECD spectra we selected a full width at half height (FWHM) of $20.0 \mathrm{~nm}$ and employed gaussian curves for the spectra and an isovalue of 0.0002 in the density differences. Details for the IR and vibronic spectra are provided in the Supplementary Materials. No solvent effects were included in the calculations.

\section{Results and Discussion}

The obtained results are summarized in Table 1 and Figures 1-6. Those for the Molecular Dynamics simulations, the analysis of the noncovalent interactions and the IR and vibronic spectra are provided in the Supplementary Materials.

Table 1. DFT(B3LYP-D3)/6-31G** optimized conformer energies.

\begin{tabular}{ccc}
\hline & & Energy (H) \\
\hline \multirow{2}{*}{ monomer } & Conformer 1 & -1476.4953010 \\
& Conformer 2 & -1476.4953009 \\
\hline \multirow{2}{*}{ dimer } & hh & -2953.0435193 \\
& ht & -2953.0400134 \\
\hline \multirow{2}{*}{$4-$ mer } & hh & -5906.1562241 \\
\hline
\end{tabular}

a)

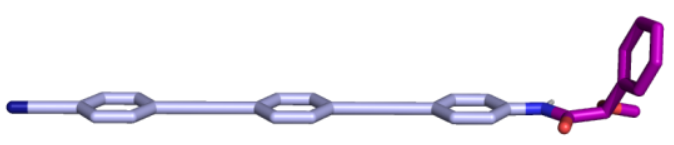

c)

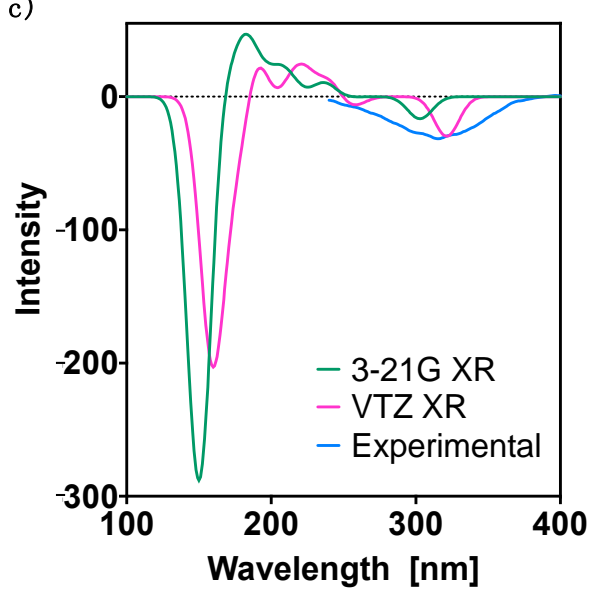

b)

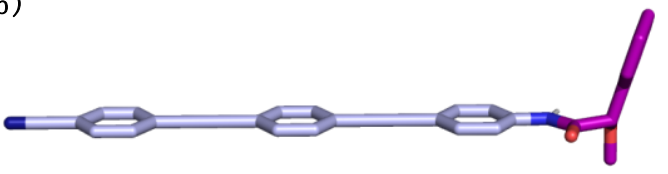

d)

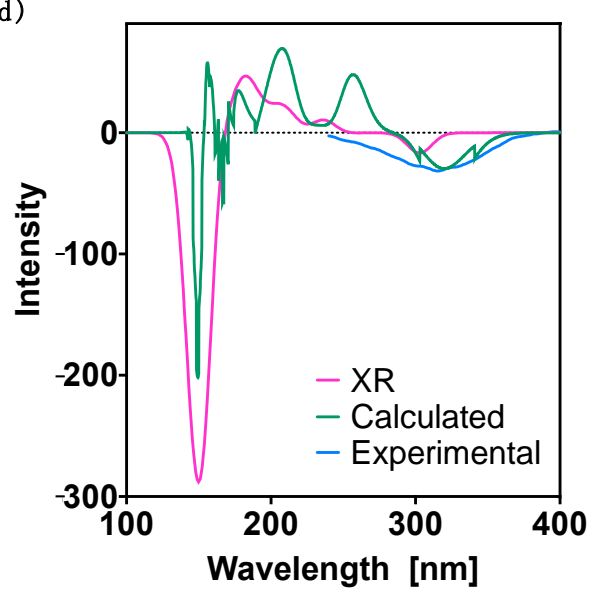

Figure 2. Oligo(phenyleneethynylene) (OPE) [(S)-1] DFT(B3LYP-D3)/6-31G** optimized geometries for (a) the most stable conformer and (b) the second most stable conformer. TD-DFT (CAM-B3LYP) ECD spectra: (c) 3-21G and cc-pVTZ (VTZ) basis set results for the X-ray (XR) geometries; (d) 3-21G basis set results obtained for the X-ray (XR) and the DFT(B3LYPD3) / 6-31G ${ }^{* *}$ optimized geometries (the latter denoted Calculated). The corresponding experimental spectra are plotted for comparison. No correction factors are included in the theoretical wavelengths. 


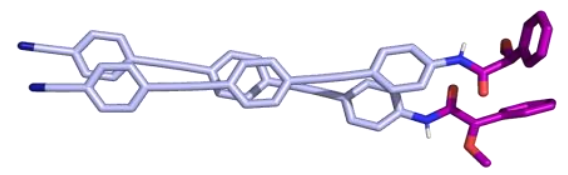

c)

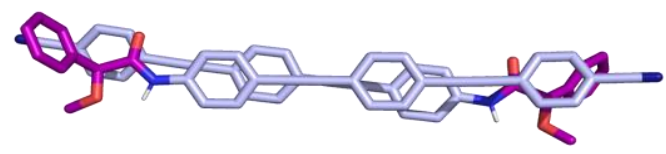

e)

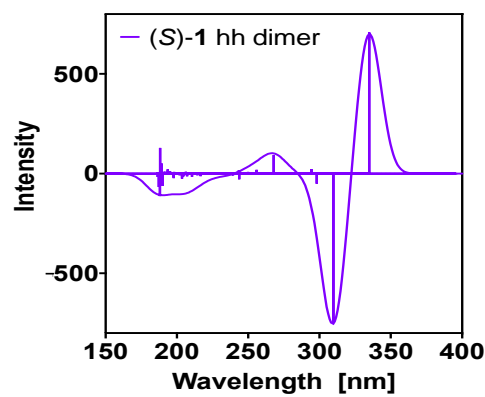

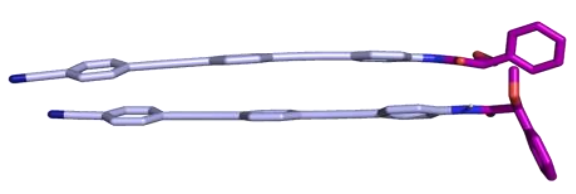

d)

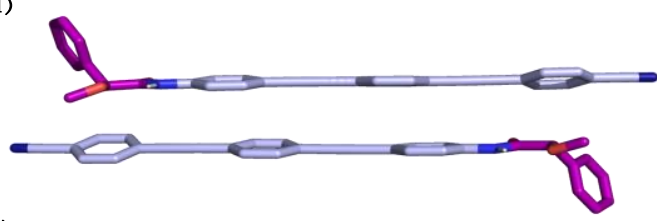

f)

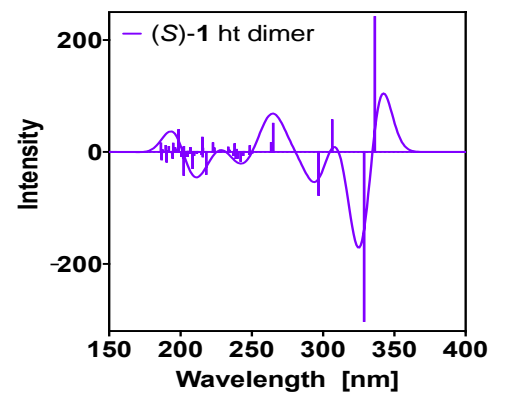

Figure 3. Oligo(phenyleneethynylene) (OPE) (S)-1 dimer DFT(B3LYP-D3)/6-31G** optimized geometries: (a) hh perpendicular view, (b) hh parallel view, (c) ht perpendicular view and (d) ht parallel view. TD-DFT (CAM-B3LYP)/3-21G ECD spectra evaluated at the DFT(B3LYP-D3)/6-31G** optimized geometries: (e) hh dimer and (f) ht dimer. No correction factors are included in the theoretical wavelengths.

a)

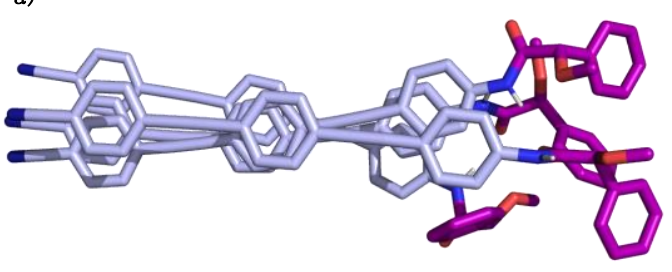

c)

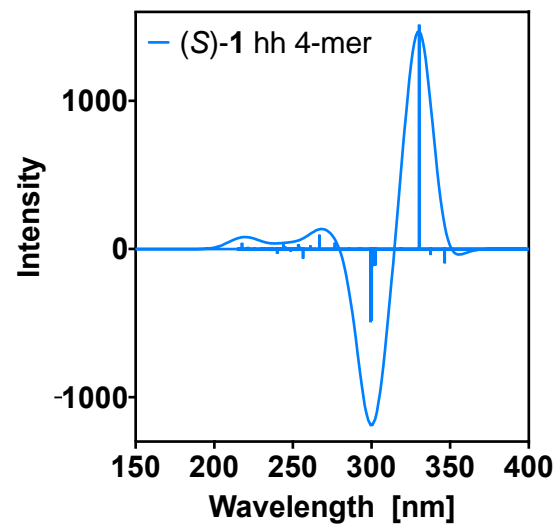

b)

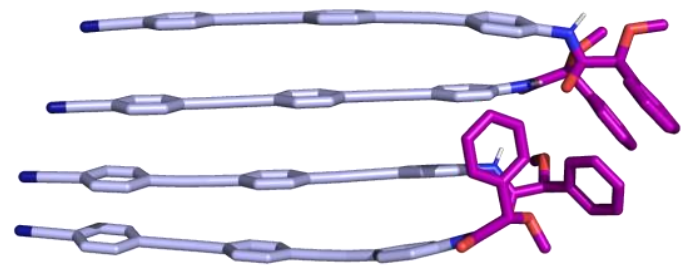

d)

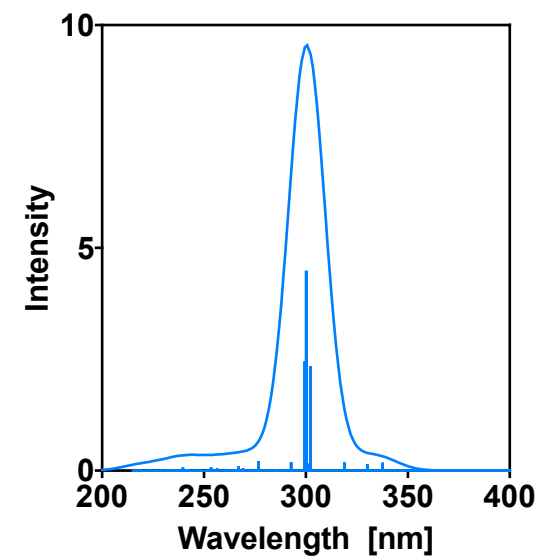

Figure 4. Oligo(phenyleneethynylene) (OPE) (S)-1 hh 4-mer DFT(B3LYP-D3)/6-31G** optimized structure: (a) perpendicular view and (b) parallel view. TD-DFT (CAM-B3LYP)/3-21G spectra evaluated at the DFT(B3LYP-D3)/6-31G ${ }^{* *}$ optimized geometry: (c) ECD and (d) UV-Vis. No correction factors are included in the theoretical wavelengths. 
a)

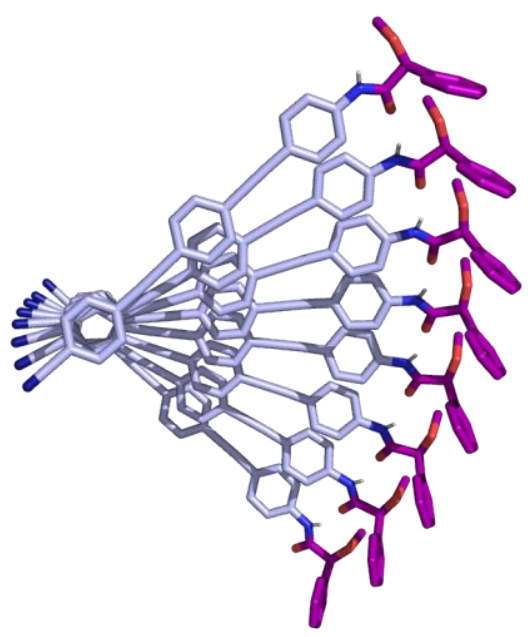

c)

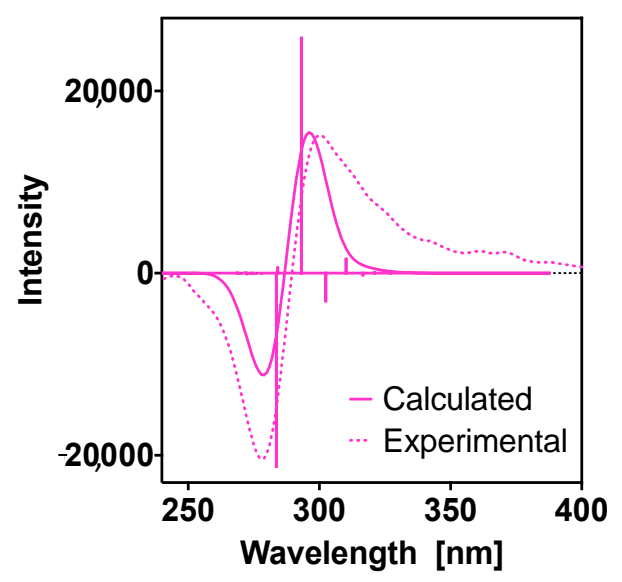

e)

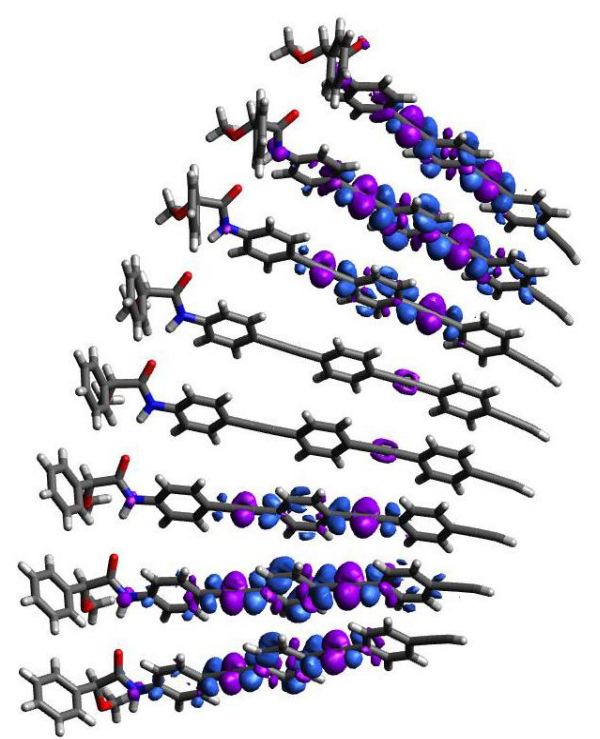

b)

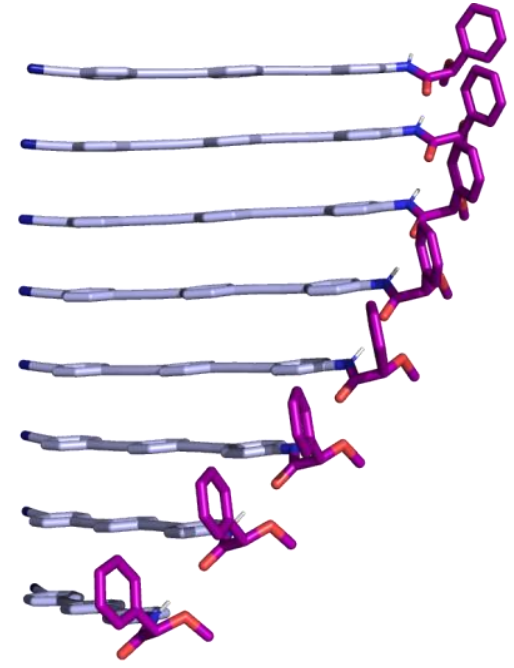

d)

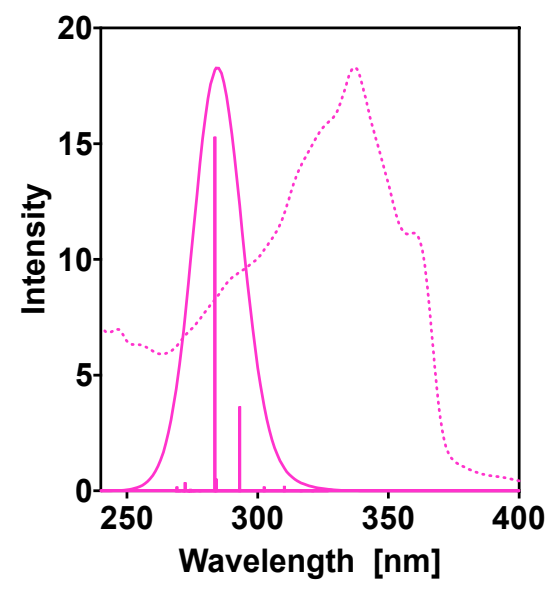

f)

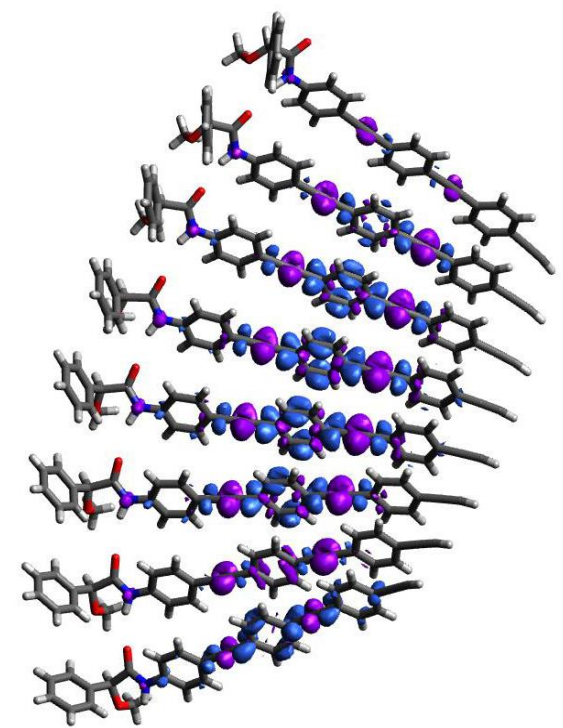

Figure 5. Oligo(phenyleneethynylene) (OPE) (S)-1 hh 8-mer structure: (a) perpendicular view and (b) hh parallel view. TD-DFT (CAM-B3LYP)/3-21G spectra: (c) ECD and (d) UV-Vis. The corresponding experimental spectra are plotted for comparison. No correction factors are included in the theoretical wavelengths. Electron density differences (purple color negative and blue positive, isovalue $=0.0002)$ for transitions: $(\mathbf{e}) S_{0} \rightarrow S_{7}$ and (f) $S_{0} \rightarrow S_{9}$. 
a)

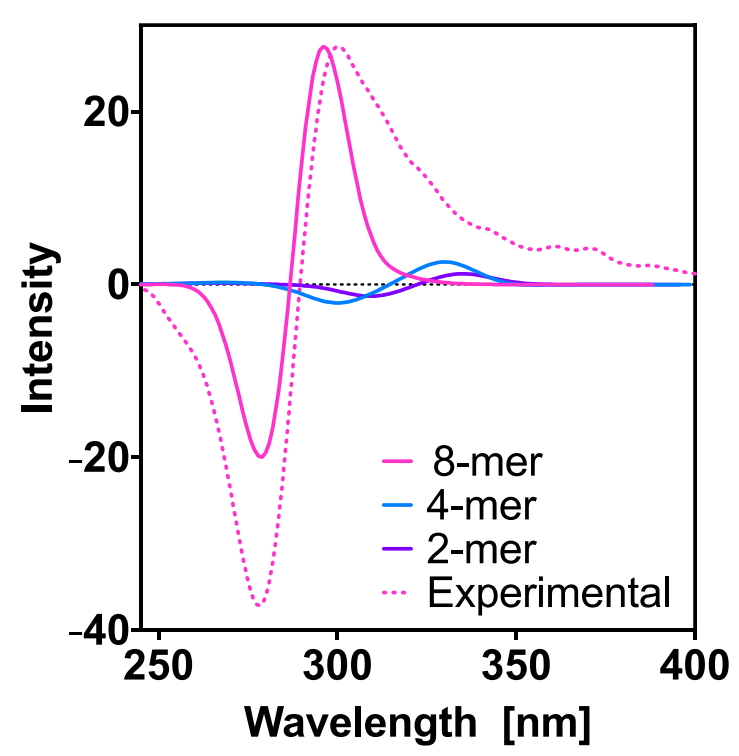

b)

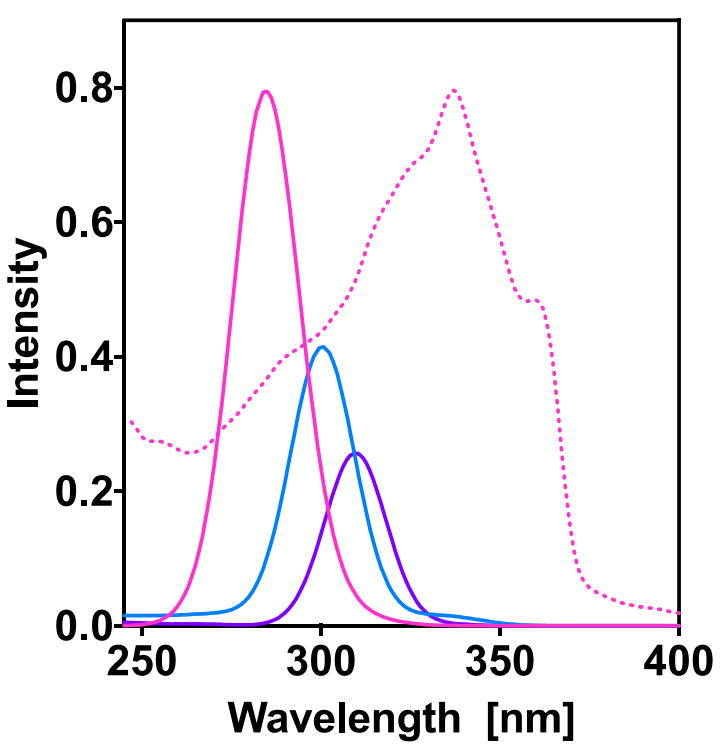

Figure 6. Effect of the aggregation on the TD-DFT (CAM-B3LYP)/3-21G (a) ECD and (b) UV-Vis spectra of oligo(phenyleneethynylene) (OPE) (S)-1 hh n-mers, $\mathrm{n}=2,4$, and 8 . The corresponding experimental spectra are included for comparison. No correction factors are considered in the theoretical wavelengths. The 8-mer intensities were normalized with respect to the experimental ones and the 2,4-mer intensities scaled with the same factors.

First theoretical studies were carried out for monomer $(S)-\mathbf{1}$. The molecule was built up using the geometry determined from X-ray studies [68] as a starting point, and the most stable conformers were obtained using the CREST program. This revealed the presence of two major conformers at room temperature that contribute significantly to the spectra. These contributions are of 70\% (degeneracy 58) for the most stable conformer (Conformer 1) and 30\% (degeneracy 52) for the second one (Conformer 2). Next, further optimization of these two structures was carried out at the DFT(B3LYP-D3)/6-31G ${ }^{* *}$ level, obtaining for Conformer 1 a $(\mathrm{O}=) \mathrm{C}-\mathrm{C} \alpha-\mathrm{O}-\mathrm{C}(\mathrm{Me})$ dihedral angle equal to $-162^{\circ}$ (Figure 2a), while Conformer 2 has a $(\mathrm{O}=) \mathrm{C}-\mathrm{C} \alpha-\mathrm{O}-\mathrm{C}(\mathrm{Me})$ dihedral angle equal to $-78^{\circ}$ (Figure $2 \mathrm{~b}$ ). The energies of these two conformers are shown in Table 1, corresponding to a population of $52.7 \%$ for Conformer 1 and of $47.3 \%$ for Conformer 2 at room temperature. We also evaluated the populations using the difference in Gibbs free energy, and the corresponding results are reported in the Supplementary Materials (Section 4). Due to the near degeneracy of the two conformers, we additionally carried out the above calculations with the $6311++\mathrm{G}(\mathrm{d}, \mathrm{p})$ basis set. The results provided similar conformers in terms of the dihedral angles- $(\mathrm{O}=) \mathrm{C}-\mathrm{C} \alpha-\mathrm{O}-\mathrm{C}(\mathrm{Me})$ dihedral angle equal to $-164^{\circ}$ and $-78^{\circ}$ for Conformer 1 and 2, respectively-and with an energy difference of $0.49 \mathrm{kcal} \mathrm{mol}^{-1}$. For consistency, we include here the $6-31 G^{* *}$ values and report the $6311++G(d, p)$ ones in the Supplementary Materials. Both molecular dynamics and DFT calculations provide Conformer 1 as the most stable.

Next, the theoretical UV-Vis and ECD spectra were evaluated. To perform these studies the TD-DFT method, use of the CAM-B3LYP functional with either the 3-21G [63] or the cc-pVTZ basis set [69], was employed. In a first approach, we evaluated the theoretical ECD spectrum for the geometry obtained from the $X$-ray studies. Comparison between the two theoretical ECD spectra, calculated using the 3-21G and the cc-pVTZ bases, and the experimental spectrum, is shown in Figure 2c. A good agreement is observed for the first Cotton band in the three ECD spectra. Moreover, in the case of the two theoretical ECD traces, the general shape of the spectra provided by the two bases is very similar, with a displacement of around $30 \mathrm{~nm}$ to the right in the case of the cc-pVTZ spectrum.

Then, the ECD spectra for the DFT(B3LYP-D3)/6-31G** optimized geometries of the two conformers with significant population at room temperature were calculated and 
combined considering the conformer contributions to get the final theoretical ECD trace. A comparison between the ECD traces obtained from the theoretical and the experimental studies, in addition to the theoretical spectrum obtained from the X-ray geometry, is shown in Figure 2d. It was found that both TD-DFT(CAM-B3LYP)/3-21G spectra-the one obtained from the conformational studies and the one obtained from the $\mathrm{X}$-ray geometry-are in agreement with the experimental one in the sign of the first Cotton effect, between 300 and $320 \mathrm{~nm}$. Also, the ECD traces obtained from the theoretical and the X-ray geometries show good agreement around $150 \mathrm{~nm}$, while the intermediate regions of the spectra are considerably different. From the DFT(B3LYP)/6311++G(d,p) conformer geometries we evaluated the corresponding ECD spectrum and report the results in the Supplementary Materials, where it is compared to the $6-31 G^{* *}$ one. When considering the populations obtained from the Gibbs free energies, only small differences are observed in the spectral bands, that are mainly due to intensity changes in the high energy regions (see Figure S6 in the Supplementary Materials).

Similar studies were carried out for a dimer of (S)-1 made by the optimized conformers of the monomeric unit. The dimer can be built up in two different ways, head-to-head (hh) (Figure 3a,b) or head-to-tail (ht) (Figure 3c,d). The former (hh) was obtained as the most stable structure, with an energy difference with respect to the latter (ht) of $2.2 \mathrm{kcal} \mathrm{mol}^{-1}$ (see Table 1). This large energy gap implies a significant difference in population of the hh with respect to the ht aggregate at room temperature, indicating a negligible contribution of the ht-conformer to the ECD spectra. Additionally, using the counterpoise correction, we evaluated the DFT(B3LYP-D3) / 6-31G** interaction energies for the hh and ht dimers, obtaining values of $-24.2 \mathrm{kcal} \mathrm{mol}^{-1}$ and $-21.8 \mathrm{kcal} \mathrm{mol}^{-1}$, respectively. This corroborates the larger stability of the hh dimer compared to the ht one. To counterpoise correct the results is important, accounting the corrections to $12.5 \mathrm{kcal} \mathrm{mol}^{-1}$ and $10.1 \mathrm{kcal} \mathrm{mol}^{-1}$ for the hh and ht dimers, respectively. The results of the analysis of the non-covalent interactions in the hh-dimer are reported in the Supplementary Materials (Figure S4) and show that van der Waals forces clearly dominate the non-covalent interactions. These results are in agreement with the van der Waals surface shown in Figure 1a, defined as that with an electron density equal to $0.001 \mathrm{au}$, and where the molecular electrostatic potential plotted reflects the electrostatic contribution to possible intermolecular interactions [70].

Theoretical ECD studies-TD-DFT(CAM-B3LYP)/3-21G—for the two orientations of the dimer show ECD traces that agree in the high wavelength region; first $(335 \mathrm{~nm}$, positive) and second cotton bands (310-330 nm, negative) (Figure 3e,f). In the low wavelength region (180 to $300 \mathrm{~nm}$ ) both ECD traces are quite different; thus, while the ht dimer displays many transitions with similar intensities (Figure 3f), the hh dimer shows just a few transitions with significant intensity (Figure 3e).

Considering the higher stability of the hh dimer, we continued studying the formation of higher order aggregates using this geometry. In this way, 4-mers were constructed from the hh dimer optimized geometry and submitted to theoretical structural studies using the CREST program. The obtained conformers were optimized at the DFT(B3LYP-D3)/6$31 \mathrm{G}^{* *}$ level, resulting in a unique preferred conformer with significant population at room temperature (Figure $4 a, b$ ).

The counterpoise corrected interaction energy was calculated at the DFT(B3LYPD3) $/ 6-31 G^{* *}$ level for the 4-mer as the difference between the complex energy and the energies of the corresponding monomers. The value obtained $\left(-91.9 \mathrm{kcal} \mathrm{mol}^{-1}\right)$ is lower by $19.3 \mathrm{kcal} \mathrm{mol}^{-1}$ than three times the dimer interaction energy, indicating that the formation of the tetramer is favored. Using the methodology outlined in reference [24], two-body contributions and cooperative effects were estimated. The former added up to $-91.7 \mathrm{kcal} / \mathrm{mol}$, being therefore the many-body contributions negligible and equal to $-0.2 \mathrm{kcal} / \mathrm{mol}$. These results clearly show that it can be a good approximation to include only two-body terms when considering the evaluation of the interaction energies in the aggregates, since these contributions amount for the most important part of the interaction energy in the 4-mer. To get insight into the cooperative effects due to the presence of extra 
monomer molecules, we calculated them using the same method and basis set and taking as reference the two first monomers in the 4-mer (Equation (3)). A value of $-13.5 \mathrm{kcal} / \mathrm{mol}$ resulted, showing that they are important at least for the small n-mers.

Subsequently, the ECD and absorption TD-DFT(CAM-B3LYP)/3-21G spectra were calculated and the results are presented in Figure $4 c, d$, respectively. Thus, the UV-Vis spectrum shows one dominant transition at $300 \mathrm{~nm}$ and two secondaries at 299 and $302 \mathrm{~nm}$, resulting in one band centered at ca. $300 \mathrm{~nm}$. On the other hand, the theoretical ECD spectrum shows two intense Cotton bands that govern the spectrum, a first positive Cotton effect at $330 \mathrm{~nm}$ and a negative one at about $300 \mathrm{~nm}$. These two bands are considerably more intense than the rest of the spectrum.

Finally, from the optimized 4-mers, 8-mer oligomers were constructed. Due to the large size of the 8-mers, we could not optimize the corresponding structures. As in all steps of the geometry assembly process visual inspection of the conformers was mandatory, in order to select the units that were adequate for an increase in cluster size; hence, often conformers with lack of proper order or monomers located at the edges of the aggregate needed to be disregarded. This resulted in the 8-mer geometry displayed in Figure $5 \mathrm{a}, \mathrm{b}$. To get further insight into the cooperative effects, we evaluated for all the n-mers $(n=1-8)$ of the 8-mer structure the interaction energy per monomer unit and convergence was achieved at around $n=5$.

The theoretical 8-mer ECD and UV-Vis TD-DFT(CAM-B3LYP)/3-21G spectra were calculated and compared to the experimental data obtained for an aggregate of $(S)-\mathbf{1}$ (Figure 5c,d, respectively). The theoretical UV-Vis spectrum shows a main band that agrees reasonably well with the experimental one. The dominant intensity at $284 \mathrm{~nm}$ is mainly due to a transition to the 9 th excited state. Interestingly, both the experimental UV-Vis spectrum of the monomer (Figure S1 in the Supplementary Materials), as well as that of the polymer, show a shoulder in the main band at larger wavelengths. In order to interpret this fact, the vibronic spectrum of the most stable conformer for $(S)-\mathbf{1}$ was evaluated. On this spectrum the influence of the density functional and the basis set differ; when improving the basis set in going from the $3-21 G$ to the $6-31 G^{* *}$ one, the spectrum suffers a displacement to larger wavelengths, whereas the opposite scenario occurs when changing the density functional from B3LYP-D3 to CAM-B3LYP-D3. The combination of the latter functional with the $6-31 G^{* *}$ basis set provided results that agree well with the experimental data and indicate that the shoulder around $360 \mathrm{~nm}$ can be assigned to the $|0>->| 0>$ vibronic transition (see the Supplementary Materials for additional information, Table S1 and Figure S1).

In the case of the theoretical ECD studies, it can be observed that the calculated spectrum is in good agreement with the experimental one (Figure 5c). In both cases a bisignate is obtained, where the two main transitions, at $293 \mathrm{~nm}$ with positive intensity and at $284 \mathrm{~nm}$ with negative intensity, are due to transitions to the 7 th and the 9 th excited states, respectively. The calculated electron density differences indicate that electron transfer from the two alkyne intermediate units to the rings in between them takes place in these excitations (Figure 5e,f).

Finally, Figure 6 summarizes all the above results and compares the different aggregate spectra previously obtained for: the dimer, tetramer and octamer of $[(S)-1]_{n}(n=2,4,8)$. The experimental results for the polymer are also provided. We can observe that as $n$ increases, the spectra undergo a bathochromic shift (to lower wavelengths). The ECD spectrum of the dimer and that of the tetramer show three Cotton effects already with a first positive Cotton band, whereas in the case of the octamer only a bisignate, which perfectly reproduces the experimental spectrum, was obtained.

The IR spectrum results for the $n=1-4$ DFT(B3LYP-D3) $/ 6-31 G^{* *}$ optimized structures are provided in the Supplementary Materials (Figure S2). Those of the monomer and the dimer display almost the same pattern, showing very small changes in going from the former to the latter. On the contrary, the 4-mer spectrum is considerably different, clearly reflecting the association. In this way, for instance, a displacement of the $\mathrm{N}-\mathrm{H}$ stretching bars to lower energies indicates the entanglement of the H-bond interactions in 
the stabilization of the aggregate. This shift is reflected in the presence of an extra band in the 4-mer spectrum, that shows three peaks instead of two in the region around $3300 \mathrm{~cm}^{-1}$ (where the terminal ethynyl-H stretching signals are also located). In a similar way, a smaller shift to lower energies of around $20 \mathrm{~cm}^{-1}$ is also observed in the case of the amide deformation band located at $1682 \mathrm{~cm}^{-1}$ in the monomer. These results corroborate that the aggregates are stabilized by $\mathrm{H}$-bond interactions.

\section{Summary and Conclusions}

Considering the wide interest linear OPEs have attracted due to their supramolecular properties and their possible applications to electronic devices, here we have carried out a detailed structural investigation on the aggregation process of $(S)-\mathbf{1}$, which yields two sheetlike nanostructures. Through systematically increasing the number of monomer units, we have determined a possible structure for the aggregate and analyzed the intermolecular forces involved in the supramolecular assembly. For the geometry optimizations we used density functional theory together with the B3LYP-D3 functional and the $6-31 G^{* *}$ basis set. Additionally, from the obtained geometries we calculated the TD-DFT(CAM-B3LYP)/3$21 \mathrm{G}$ absorption and circular dichroism spectra, that are in agreement with the experimental results available. Therefore, we can conclude that the methodology used can be expected to provide an efficient approximation to the structure and spectra in routine studies of similar aggregates and polymers.

Supplementary Materials: The following supplementary data are available online. Molecular Dynamics study, Table S1: Molecular Dynamics main results, Table S2: Geometries used in the evaluation of the spectra, Table S3: Monomer vibronic spectrum transitions, Figure S1: MD conformers for the monomer, Figure S2: MD most stable conformers for the dimer, Figure S3: MD most stable conformers for the 4-mer, Figure S4: Analysis of the dimer intermolecular interactions, Figures S5 and S6: Additional ECD spectra for the monomer, Figure S7: Monomer vibronic spectrum, Figure S8: Monomer and 4-mer IR spectra.

Author Contributions: B.F.: investigation, writing—review \& editing, Z.F.: investigation, writingreview \& editing, E.Q.: investigation, writing—review \& editing, F.F.: investigation, writing-review \& editing. All authors have read and agreed to the published version of the manuscript.

Funding: This research was funded by Ministerio de Ciencia e Innovación, grant number PID2019107307RB-100; Xunta de Galicia, grants number and ED431C 2018/30, ED431C 2017/17 and ED431G 2019/03; and the European Regional Development Fund (ERDF).

Acknowledgments: We thank Servicio de Nanotecnología y Análisis de Superficies (CACTI, UVIGO). Z.F. thanks Xunta de Galicia for her PhD fellowship and B.F. acknowledges CESGA for computational time.

Conflicts of Interest: The authors declare no conflict of interest. The funders had no role in the design of the study; in the collection, analyses, or interpretation of data; in the writing of the manuscript, or in the decision to publish the results.

Sample Availability: Samples of the compounds are not available.

Geometry Availability: The optimized geometries are included in the Supplementary Materials.

\section{References}

1. Li, Y.; Hammoud, A.; Bouteiller, L.; Raynal, M. Emergence of homochiral benzene-1,3,5-tricarboxamide helical assemblies and catalysts upon addition of an achiral monomer. J. Am. Chem. Soc. 2020, 142, 5676-5688. [CrossRef]

2. Raynal, M.; Portier, F.; van Leeuwen, P.W.N.M.; Bouteiller, L. Tunable asymmetric catalysis through ligand stacking in chiral rigid rods. J. Am. Chem. Soc. 2013, 135, 17687-17690. [CrossRef] [PubMed]

3. Huerta, E.; van Genabeek, B.; Lamers, B.A.G.; Koenigs, M.M.E.; Meijer, E.W.; Palmans, A.R.A. Triggering activity of catalytic rod-like supramolecular polymers. Chem. Eur. J. 2015, 21, 3682-3690. [CrossRef]

4. Desmarchelier, A.; Caumes, X.; Raynal, M.; Vidal-Ferran, A.; van Leeuwen, P.W.N.M.; Bouteiller, L. Correlation between the selectivity and the structure of an asymmetric catalyst built on a chirally amplified supramolecular helical scaffold. J. Am. Chem. Soc. 2016, 138, 4908-4916. [CrossRef] 
5. $\quad$ Saint-Denis, T.G.; Zhu, R.-Y.; Chen, G.; Wu, Q.-F.; Yu, J.-Q. Enantioselective C(sp3)-H bond activation by chiral transition metal catalysts. Science 2018, 359, 1-14. [CrossRef] [PubMed]

6. Dumele, O.; Chen, J.; Passarelli, J.V.; Stupp, S.I. Supramolecular Energy Materials. Adv. Mater. 2020, 32, 1907247. [CrossRef]

7. Schenning, A.P.H.J.; Meijer, E.W. Supramolecular electronics; nanowires from self-assembled $\pi$-conjugated systems. Chem. Commun. 2005, 26, 3245-3258. [CrossRef]

8. Yamaguchi, Y.; Ochi, Y.; Miyamura, S.; Tanaka, T.; Kobayashi, S.; Wakamiya, T.; Matsubara, Y.; Yoshida, Z. Rigid molecular architectures that comprise a 1,3,5-trisubstituted benzene core and three oligoaryleneethynylene arms: Light-emitting characteristics and $\pi$ conjugation between the arms. J. Am. Chem. Soc. 2006, 128, 4504-4505. [CrossRef]

9. Yamamoto, Y.; Fukushima, T.; Suna, Y.; Ishii, N.; Saeki, A.; Seki, S.; Tagawa, S.; Taniguchi, M.; Kawai, T.; Aida, T. Photoconductive coaxial nanotubes of molecularly connected electron donor and acceptor layers. Science 2006, 314, 1761-1764. [CrossRef]

10. Tovar, J.D. Supramolecular Construction of Optoelectronic Biomaterials. Acc. Chem. Res. 2013, 46, 1527-1537. [CrossRef]

11. Zhang, J.; Dong, S.; Zhang, K.; Liang, A.; Yang, X.; Huang, F.; Cao, Y. A series of blue supramolecular polymers with different counterions for polymer light-emitting diodes. Chem. Commun. 2014, 50, 8227-8230. [CrossRef]

12. Goor, O.J.G.M.; Hendrikse, S.I.S.; Dankers, P.Y.W.; Meijer, E.W. From supramolecular polymers to multi-component bio- materials. Chem. Soc. Rev. 2017, 46, 6621-6637. [CrossRef]

13. Biswas, S.; Kinbara, K.; Oya, N.; Ishii, N.; Taguchi, H.; Aida, T. A Tubular Biocontainer: Metal Ion-Induced 1D Assembly of a Molecularly Engineered Chaperonin. J. Am. Chem. Soc. 2009, 131, 7556-7557. [CrossRef]

14. Aida, T.; Meijer, E.W.; Stupp, S.I. Functional Supramolecular Polymers. Science 2012, 335, 813-817. [CrossRef]

15. Bakker, M.H.; Lee, C.C.; Meijer, E.W.; Dankers, P.Y.W.; Albertazzi, L. Multicom-ponent Supramolecular Polymers as a Modular Platform for Intracellular Delivery. ACS Nano 2016, 10, 1845-1852. [CrossRef] [PubMed]

16. Kulkarni, C.; Meijer, E.W.; Palmans, A.R.A. Cooperativity Scale: A Structure-Mechanism Correlation in the Self-Assembly of Benzene-1,3,5-tricarboxiamides. Acc. Chem. Res. 2017, 50, 1928-1936. [CrossRef]

17. de Greef, T.F.A.; Smulders, M.M.J.; Wolffs, M.; Schenning, A.P.H.J.; Sijbesma, R.P.; Meijer, E.W. Supramolecular Polymerization. Chem. Rev. 2009, 109, 5687-5754. [CrossRef]

18. Rodríguez, R.; Ignés-Mullol, J.; Sagués, F.; Quiñoá, E.; Riguera, R.; Freire, F. Helical sense selective domains and enantiomeric superhelices generated by Langmuir-Schaefer deposition of an axially racemic chiral helical polymer. Nanoscale 2016, 8, 3362-3367. [CrossRef] [PubMed]

19. Sakurai, S.-I.; Okoshi, K.; Kumaki, J.; Yashima, E. Two-Dimensional Surface Chirality Control by Solvent-Induced Helicity Inversion of a Helical Polyacetylene on Graphite. J. Am. Chem. Soc. 2006, 128, 5650-5651. [CrossRef] [PubMed]

20. Okoshi, K.; Sakurai, S.-I.; Ohsawa, J.K.; Yashima, E. Two-Dimensional Hierarchical Self-Assembly of One-Handed Helical Polymers on Graphite. Angew. Chem. Int. Ed. 2006, 45, 1245-1248.

21. Díaz-Cabrera, S.; Dorca, Y.; Calbo, J.; Aragó, J.; Gómez, R.; Ortí, E.; Sánchez, L. Hierarchy of Asymmetry at Work; ChainDependent Helix-to-Helix Interactions in Supramolecular Polymers. Chem. Eur. J. 2018, 24, 2826-2831. [CrossRef]

22. Greciano, E.E.; Calbo, J.; Ortí, E.; Sánchez, L. N-Annulated Perylene Bisimides to Bias the Differentiation of Metastable Supramolecular Assemblies into J- and H-Aggregates. Angew. Chem. Int. Ed. 2020, 132, 17670-17677. [CrossRef]

23. Wehner, M.; Röhr, M.I.S.; Bühler, M.; Stepanenko, V.; Wagner, W.; Würthner, F. Supramolecular Polymorphism in One-Dimensional Self-Assembly by Kinetic Pathway Control. J. Am. Chem. Soc. 2019, 141, 6092-6107. [CrossRef]

24. Ogi, S.; Stepanenko, V.; Sugiyasu, K.; Takeuchi, M.; Würthner, F. Mechanism of Self-Assembly Process and Seeded Supramolecular Polymerization of Perylene Bisimide Organogelator. J. Am. Chem. Soc. 2015, 137, 3300-3307. [CrossRef]

25. Würthner, F.; Möller, C.R.S.; Fimmel, B.; Ogi, S.; Leowanawat, P.; Schmidt, D. Perylene Bisimide Dye Assemblies as Archetype Functional Supramolecular Materials. Chem. Rev. 2016, 116, 962-1052. [CrossRef]

26. Weyandt, E.; ter Huurne, G.M.; Vantomme, G.; Markvoort, A.J.; Palmans, A.R.A.; Meijer, E.W. Photodynamic Control of the Chain Length in Supramolecular Polymers: Switching an Intercalator into a Chain Capper. J. Am. Chem. Soc. 2020, 142, 6295-6303. [CrossRef]

27. Smulders, M.M.J.; Filot, I.A.W.; Leenders, J.M.A.; van der Schoot, P.; Palmans, A.R.A.; Schenning, A.P.H.J.; Meijer, E.W. Tuning the Extent of Chiral Amplification by Temperature in a Dynamic Supramolecular Polymer. J. Am. Chem. Soc. 2010, 132, 611-619. [CrossRef]

28. Smulders, M.M.J.; Stals, P.J.M.; Mes, T.; Paffen, T.F.E.; Schenning, A.P.H.J.; Palmans, A.R.A.; Meijer, E.W. Probing the Limits of the Majority-Rules Principle in a Dynamic Supramolecular Polymer. J. Am. Chem. Soc. 2010, 132, 620-626. [CrossRef] [PubMed]

29. Hifsudheen, M.; Mishra, R.K.; Vedhanarayanan, B.; Praveen, V.K.; Ajayaghosh, A. The Helix to Super-Helix Transition in the Self-Assembly of $\pi$-Systems: Superseding of Molecular Chirality at Hierarchical Level. Angew. Chem. Int. Ed. 2017, 56, 12634-12638. [CrossRef]

30. García, F.; Fernández, G.; Sánchez, L. Modulated Morphology in the Self-Organization of a Rectangular Amphiphile. Chem. Eur. J. 2009, 15, 6740-6747. [CrossRef]

31. Fernández, G.; García, F.; Aparicio, F.; Matesanz, E.; Sánchez, L. Two-dimensional self-organization of rectangular OPE amphiphiles into microcrystalline lamellae. Chem. Commun. 2009, 46, 7155-7157. [CrossRef] [PubMed]

32. Aparicio, F.; García, F.; Fernández, G.; Matesanz, E.; Sánchez, L. Mirror Helices and Helicity Switch at Surfaces Based on Chiral Triangular-Shape Oligo(phenylene ethynylenes). Chem. Eur. J. 2011, 17, 2769-2776. [CrossRef] [PubMed] 
33. García, F.; Korevaar, P.A.; Verlee, A.; Meijer, E.W.; Palmans, A.R.A.; Sánchez, L. The influence of $\pi$-conjugated moieties on the thermodynamics of cooperatively self-assembling tricarboxamides. Chem. Commun. 2013, 49, 8674-8676. [CrossRef]

34. Buendía, J.; Calbo, J.; García, F.; Aragó, J.; Viruela, P.M.; Ortí, E.; Sánchez, L. Helical supramolecular polymerization of C3-symmetric amides and retroamides: On the origin of cooperativity and handedness. Chem. Commun. 2016, 52, 6907-6910. [CrossRef]

35. Buendía, J.; García, F.; Yélamos, B.; Sánchez, L. Transfer and amplification of chirality in Phe-based C3-symmetric non-ionic amphiphiles. Chem. Commun. 2016, 52, 8830-8833. [CrossRef]

36. Zhang, W.; Jin, W.; Fukushima, T.; Ishii, N.; Aida, T. Dynamic or Nondynamic? Helical Trajectory in Hexabenzocoronene Nanotubes Biased by a Detachable Chiral Auxiliary. J. Am. Chem. Soc. 2013, 135, 114-117. [CrossRef]

37. Jin, W.; Fukushima, T.; Niki, M.; Kosaka, A.; Ishii, N.; Aida, T. Self-Assembled Graphitic Nanotubes with One-Handed Helical Arrays of a Chiral Amphiphilic Molecular Graphene. Proc. Natl. Acad. Sci. USA 2005, 102, 10801-10806. [CrossRef]

38. Zhang, W.; Jin, W.; Fukushima, T.; Ishii, N.; Aida, T. Metal-Ion-Coated Graphitic Nanotubes: Controlled Self-Assembly of a Pyridyl-Appended Gemini-Shaped Hexabenzocoronene Amphiphile. Angew. Chem. Int. Ed. 2009, 48, 4747-4750. [CrossRef]

39. Dorca, Y.; Greciano, E.E.; Valera, J.S.; Gómez, R.; Sánchez, L. Hierarchy of Asymmetry in Chiral Supramolecular Polymers: Toward Functional, Helical Supramolecular Structures. Chem. Eur. J. 2019, 25, 5848-5864. [CrossRef]

40. Jagtap, S.P.; Mukhopadhyay, S.; Coropceanu, V.; Brizius, G.L.; Brédas, J.-L.; Collard, D.M. Closely Stacked Oligo(phenylene ethynylene)s: Effect of $\pi$-Stackingon the Electronic Properties of Conjugated Chromophores. J. Am. Chem. Soc. 2012, 134, 7176-7185. [CrossRef]

41. Xiao, X.; Nagahara, L.A.; Rawlett, A.M.; Tao, N. Electrochemical Gate-Controlled Conductance of Single Oligo(phenylene ethynylene)s. J. Am. Chem. Soc. 2005, 127, 9235-9240. [CrossRef] [PubMed]

42. Philips, D.S.; Kartha, K.K.; Politi, A.T.; Krügger, T.; Albuquerque, R.Q.; Fernández, G. Interplay between H-Bonding and Preorganization in the Evolution of Self-Assembled Systems. Angew. Chem. Int. Ed. 2019, 58, 4732-4736. [CrossRef] [PubMed]

43. Mayoral, M.J.; Rest, C.; Schellheimer, J.; Stepanenko, V.; Fernández, G. Narcissistic versus Social Self-Sorting of Oligophenyleneethynylene Derivatives: From Isodesmic Self-Assembly to Cooperative Co-Assembly. Chem. Eur. J. 2012, 18, 15607-15611. [CrossRef] [PubMed]

44. Rudolph, T.; Allampally, N.K.; Fernández, G.; Schacher, F.H. Controlling Aqueous Self-Assembly Mechanisms by Hydrophobic Interactions. Chem. Eur. J. 2014, 20, 13871-13875. [CrossRef] [PubMed]

45. Albert, S.K.; Golla, M.; Thelu, H.V.P.; Krishnan, N.; Varghese, R. A pH-Responsive DNAsome from the Self-Assembly of DNA-Phenyleneethynylene Hybrid Amphiphile. Chem. Eur. J. 2017, 23, 8348-8352. [CrossRef]

46. Langenstroer, A.; Kartha, K.K.; Dorca, Y.; Dröste, J.; Stepanenko, V.; Albuquerque, R.Q.; Hansen, M.R.; Sanchez, L.; Fernán-dez, G. Unraveling Concomitant Packing Polymorphism in Metallosupramolecular Polymers. J. Am. Chem. Soc. 2019, 141, 5192-5200. [CrossRef]

47. Fernández, Z.; Fernández, B.; Quiñoá, E.; Freire, F. Dynamic and Individual Supramolecular Helices: The Complex Aggregation Pathway of a Short, Asymmetric and Chiral Oligo( $p$-phenyleneethynylene). Angew. Chem. Int. Ed. 2021. [CrossRef]

48. Fernández, B.; Rodríguez, R.; Rizzo, A.; Quiñoá, E.; Riguera, R.; Freire, F. Predicting the Helical Sense of Poly(phenylacetylene)s from their Electron Circular Dichroism Spectra. Angew. Chem. Int. Ed. 2018, 57, 3666-3670. [CrossRef]

49. Grimme, S. Conformer-Rotamer Ensemble Sampling Tool (CREST). J. Chem. Theor. Comput. 2019, 15, 2847-2862. [CrossRef]

50. Hohenberg, P.; Kohn, W. Inhomogeneous Electron Gas. Phys. Rev. 1964, 136, B864-B871. [CrossRef]

51. Kohn, W.; Sham, L.J. Self-Consistent Equations Including Exchange and Correlation Effects. Phys. Rev. 1965, 140, A1133-A1138. [CrossRef]

52. Becke, A.D. Density functional thermochemistry. III. The role of exchange. J. Chem. Phys. 1993, 98, 5648-5652. [CrossRef]

53. Stephens, P.J.; Devlin, F.J.; Chabalowski, C.F.; Frisch, M.J. Ab Initio Calculation of Vibrational Absorption and Circular Dichroism Spectra using Density Functional Force Fields. J. Phys. Chem. 1994, 98, 11623-11627. [CrossRef]

54. Grimme, S.; Ehrlich, S.; Goerigk, L. Effect of the damping function in dispersion corrected density functional theory. J. Comput. Chem. 2011, 32, 1456-1465. [CrossRef]

55. Hehre, W.J.; Ditchfield, R.; Pople, J.A. Self-Consistent Molecular Orbital Methods. XII. Further Extensions of Gaussian-Type Basis Sets for Use in Molecular Orbital Studies of Organic Molecules. J. Chem. Phys. 1972, 56, 2257-2261. [CrossRef]

56. Boys, S.F.; Bernardi, F. The calculation of small molecular interactions by the differences of separate total energies. Some procedures with reduced errors. Mol. Phys. 1970, 19, 553-566. [CrossRef]

57. Johnson, E.R.; Keinan, S.; Mori-Sánchez, P.; Contreras-García, J.; Cohen, A.J.; Yang, W. Revealing Noncovalent Interactions. J. Am. Chem. Soc. 2010, 132, 6498-6506. [CrossRef]

58. Baranowska, A.; Zawada, A.; Fernández, B.; Bartkowiak, W.; Kedziera, D.; Kaczmarek-Kedziera, A. Interaction-induced electric properties and cooperative effects in model systems. Phys. Chem. Chem. Phys. 2010, 12, 852-862. [CrossRef] [PubMed]

59. Scheiner, S. Hydrogen Bonding: A Theoretical Perspective; Oxford University Press: Oxford, UK, 1997.

60. Fernández, B.; Rodríguez, R.; Quiñoá, E.; Riguera, R.; Freire, F. Decoding the ECD spectra of Poly(phenylacetylene)s: Structural significance. ACS Omega 2019, 4, 5233-5240. [CrossRef]

61. Runge, E.; Gross, E.K.U. Density-Functional Theory for Time-Dependent Systems. Phys. Rev. Lett. 1984, 52, 997-1000. [CrossRef]

62. Yanai, Y.; Tew, D.P.; Handy, N.C. A New Hybrid Exchange-Correlation Fuctional Using the Coulomb-attenuating Method (CAM-B3LYP). Chem. Phys. Lett. 2005, 393, 51-57. [CrossRef] 
63. Binkley, J.S.; Pople, J.A.; Hehre, W.J. Self-consistent Molecular Orbital Methods. 21. Small Split-valence Basis Sets for First-row Elements. J. Am. Chem. Soc. 1980, 102, 939-947. [CrossRef]

64. Frisch, M.J.; Trucks, G.W.; Schlegel, H.B.; Scuseria, G.E.; Robb, M.A.; Cheeseman, J.R.; Scalmani, G.; Barone, V.; Petersson, G.A.; Nakatsuji, H.; et al. Gaussian 16; Revision C.01; Gaussian Inc.: Wallingford, CT, USA, 2016.

65. Neese, F. The ORCA program system. WIREs Comput. Mol. Sci. 2012, 2, 73-78. [CrossRef]

66. Allouche, A.R. Gabedit-A Graphical User Interface for Computational Chemistry Softwares. J. Comput. Chem. 2011, 32, 174-182. [CrossRef]

67. Hanwell, M.D.; Curtis, D.E.; Lonie, D.C.; Vandermeersch, T.; Zurek, E.; Hutchison, G.R. Avogadro: An Advanced Semantic Chemical Editor, Visualization, and Analysis Platform. J. Cheminform. 2012, 4, 17. [CrossRef] [PubMed]

68. Fernández, Z.; Fernández, B.; Quiñoá, E.; Freire, F. Chiral information harvesting in helical poly(acetylene) derivatives using oligo(p-phenyleneethynylene)s as spacers. Chem. Sci. 2020, 11, 7182-7187. [CrossRef]

69. Dunning, T.H. Gaussian basis sets for use in correlated molecular calculations. I. The atoms boron through neon and hydrogen. J. Chem. Phys. 1989, 90, 1007-1023. [CrossRef]

70. Liu, Z.; Chen, Q. Intermolecular interaction characteristics of the all-carboatomic ring, cyclo[18]carbon: Focusing on molecular absorption and stacking. Carbon 2021, 171, 514-523. [CrossRef] 